\title{
Cultural Adoption in World of Warcraft
}

\author{
Zihao $\mathrm{Wu}^{1, \mathrm{a}}$ \\ School of Finance, Central University of Finance and Economics, Beijing, 100081, China \\ *Corresponding author. Email: angela@cas-harbour.org
}

\begin{abstract}
In recent years, China has increased the investment in cultural industry, including the electronic game industry which has received the corresponding attention. However, in the process of its development, several problems emerge, such as game stagnation and lack of development of online games. Therefore, this paper analyzes the current situation of the development of Warcraft electronic game industry and the impact of its success, in order to provide some suggestions for the future development of Chinese electronic games.
\end{abstract}

Keywords: Cultural adoption, World of Warcraft, computer game

\section{INTRODUCTION}

With the rousing excitement, people all over the world start to play video games and a large number of people are addicted to them. According to the statistics, there are currently more than 500 million people playing video games in China. As a result, some people have a negative view of video games, especially the older generation. However, video games can allow players to be truly integrated into the virtual world and interacting with the creators' brilliant ideas. The production of video games usually requires conceptual art, which is aesthetically pleasing and has a high artistic value. Popular video games have their unique culture. By critically analyzing video games, in particular the World of Warcraft, this paper will argue that video game is an excellent prism to reveal essential sentiments about fluidity of cultural images and forms. Video game is a sensitive barometer of the culture and time that freely adopts and adapts historical characters to promote a universal aesthetic that can be interpreted independent of time and place. Video game imagines a new world that is both in and out of this world and only the thrill and excitement of games can have that effect.

In the history of aesthetics, several aestheticians have identified the relationship between games and art. Immanuel Kant, Johann Schiller, Sigmund Freud and others have all expressed influential representative views and opinions. Whether or not readers consider electronic games as an art form, the value of electronic games in modern society should not be ignored. Therefore, the study of electronic games should be carried out in depth. Made by an American gaming company, World of Warcraft has many elements of European and American culture, such as castles, knights and dragons. However, in this magical world, other cultural elements from China, Egypt and Nordic are also presented. Overall, the use of these cultural elements has achieved significant positive results. Thus, it is of great significance to study the cultural adoption of Warcraft culture for the development of video games in China.

\section{LITERATURE REVIEW}

\subsection{Cultural Adoption}

Cultural adoption is the phenomenon of borrowing the cultural resources of foreign countries or other nationalities that do not belong to the local area, thus forming influence on the local culture and creating new cultural products. Cultural adoption is considered to be the use of cultural elements (objects, styles, themes, etc.) in one cultural background by people in another[1]. "Adoption is different from appropriation since the latter may assume some forms of exploitation or power inequities. Adoption, however, assumes bringing in an element that you did not make yourself but raising it as if it were your own, similar to the adoption of a child[2]." Power, historical factors, economic, ethical and even legal factors are interwoven to form a complex context for discussing cultural adoption[3]. Thus cultural adoption has fewer negative connotations and can be served as a more valuable analytical tool. From the perspective of cultural communication, cultural adoption is a double-edged sword. In order to eliminate cross-cultural barriers, cultural appropriation should not only go through a deculturation process of eliminating, desalinating and rewriting cultural differences, but also generate new cultural contents and forms through combining the mainstream ideology of the author's own era, namely the so-called reculturalization process[4]. An important feature of American culture is its active participation in cultural adoption. In Hollywood, for example, although Hollywood road of the Chinese culture still experienced from $\mathrm{Fu}$ Manchu to Charlie Chan to Hua Mulan and Kung fu panda, it is undeniable that the Chinese images in the movie in constant plumps and westerners inherent racial prejudice as well as the influence of the different cultural patterns are gradually weakened. This is not only the result of its own correction, but also the positive intervention of Chinese culture. The rising international status of China has helped reverse her long-standing image and Chinese culture is 
taking the initiative to go out and participate in the production of these films.

\subsection{Video Games}

Chinese research on the electronic game industry started at the beginning of the 21 st century, and the early research from the perspective of economics is relatively simple. However many of the ideas and expectations that had been put forward have become reality. Chen Liu and Zhou Qin analyzed the market environment, consumer potential and industrial model of the online game industry from the perspective of industrial analysis. They believed that the online game industry is a new industry with great influence through the correct guidance of the game industry[5]. Feng Yuchao defined e-sports and believed that E-sports would further develop towards popularization and professionalization as well as elaborated the current situation of international E-sports. The comparison shows that China's E-sports is still in a relatively primary stage and the continuous improvement of relevant systems will promote its further development[6]. Yang Jian and Guo Jianzhong analyzed the specific situation of the development of China's online game industry, and took Shanda company as an example, pointing out that the rapid development of information technology, the effective elimination of piracy and strong interaction are the important reasons for the rapid development of online games, also made suggestions on the development of online game industry from the perspectives of culture, policy and technology[7]. Xu Tao reviewed the formation process of Chinese video game industry, elaborating the nature and positioning of Chinese game industry, and carried out a more detailed horizontal classification combined with the government, society, science and technology and other factors to restore Chinese game industry market and put forward suggestions for its future development[8]. Han Lei studied the upstream link, midstream service link and downstream channel link of the video game industry in the point of industrial chain, and discussed the profit model of each part of the video game industry chain from the perspective of core value, profit object, profit leverage, income source and profit barrier[9]. The development momentum of China's video games is good, but there still lacks of hard conditions in the game technology. World of Warcraft is an excellent game which is popular around the world and through the analysis of it, some references for the development of video games in China can be provided.

\section{THE CULTURAL ADOPTION IN WORLD OF WARCRAFT}

\subsection{Features of World of Warcraft}

World of Warcraft is the first massively multiplayer online role-playing game created by Blizzard Entertainment, on basis of Irvine city in California in 2004. The plot of real-time strategy game is based on historical events and actual military heroes, which includes a complete historical background timeline. Players take risks in this game, complete missions, embark on new adventures, explore the unknown worlds, and conquer monsters. World of Warcraft gives players an opportunity to act as characters in the magic world.

World of Warcraft is a melting pot type of game and it contains many real-world cultural elements. There are heroes transformed from Nordic gods, Egyptian-style architecture and typical Chinese cuisine. These cultural elements allow players to be quickly integrated into the World of Warcraft and be deeply attracted to it.

\subsection{Cultural Adoption in World of Warcraft}

As mentioned earlier, there are lots of cultural adoptions going on in World of Warcraft. Here are some images in World of Warcraft which illustrate its specific applications of cultural adoption.

\subsubsection{Greek culture}

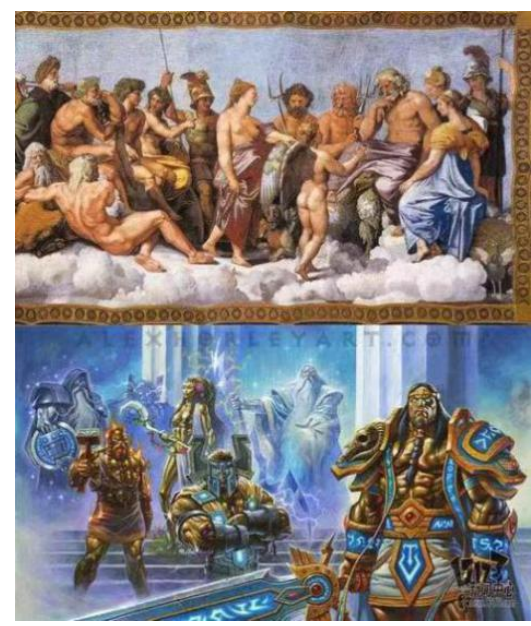

Figure 1 Greek mythology

The Titans are a race that combined the old gods of Greek mythology with the new gods of Olympus. The Titan characters in World of Warcraft look and dress like the gods of Greek mythology. Amanthor, the father of all gods, seems to be a combination of Uranus, the god of heaven, and Zeus, the father of all gods; while the name of pantheon, the Titan high council, comes from the ancient 
Roman buildings dedicated to the Greek gods, which also alludes to the resolution of the gods on Mount Olympus. In addition, many similar gods and stories from Greek mythology can be found in the pantheon Titan. Titans are adapted from gods in Greek mythology. This kind of character setting makes it easy for players to understand Titan's powerful abilities.

\subsubsection{Nordic culture}

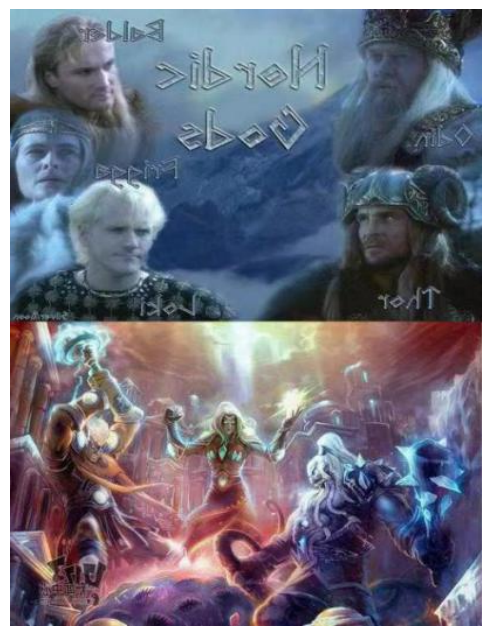

Figure 2 Nordic mythology

The name Odur comes from the Norse god of winter, which is quite in tune with the snow and ice of the storm mountains in World of Warcraft. Freya is the Norse goddess of life, with the same name and fighting style. Thorim, Lord of the storms, is the counterpart of Thor, who can also ride lightning. Mirmiron is the intellectual giant Mimir, who has a similar talent for creativity. As for Hodir, it is a combination of Odin, a Norse god, and an ice giant. For example, Thorim has the ability to control lightning, much like Thor. For Nordic players, it is easy to associate Thor with Thorim. For players in other parts of the world, such a setup is also attractive because the myths that have survived are proved to have a wide audience. Rather than creating a game character out of thin air, an adaptation of a mythical character has a greater chance of gaining players' approval.

\subsubsection{Egyptian culture}

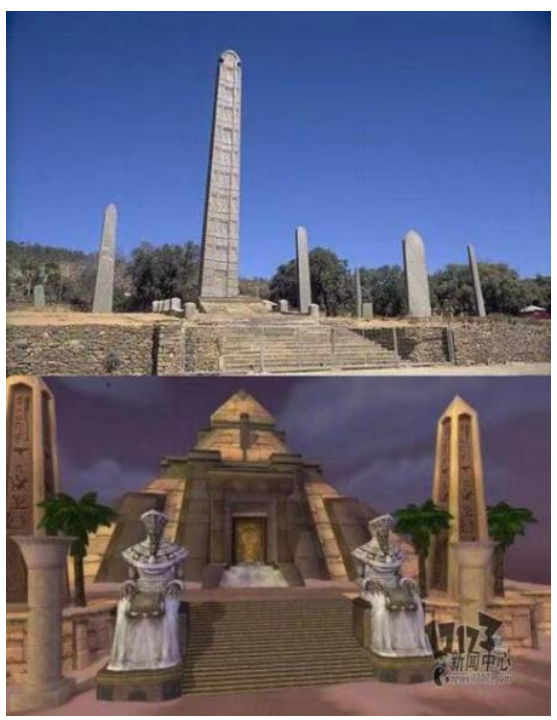

Figure 3 Egyptian culture

In the far south of Kalimdor, an ancient desert civilization, Torvill, became a part of the game in 2011. In fact, from the moment players come to this area, the strong ancient Egyptian wind blow on their faces. For ordinary players, it is the most intuitive impression than the magnificent pyramid. With closely look, the Egyptian elements in Ordum can be seen everywhere. First of all, everyone knows about pyramids, but are there only pyramids in Egypt? Obviously not. So what else can be found in Ordum that is a clear characteristic of Egyptian civilization? The obelisk, which is one of the symbols of the ancient Egyptian worship of the sun god. Its square base and steeple are the main features. Various statues, whether majestic or half-buried, are also based on the gods of Egyptian mythology. Egyptian culture is full of mystery. Ordum is also a mysterious area in World of Warcraft, and it is easier to make players feel this mystery by applying the setting of Egyptian culture, so as to promote the development of game's subsequent plots. 


\subsubsection{Chinese culture}

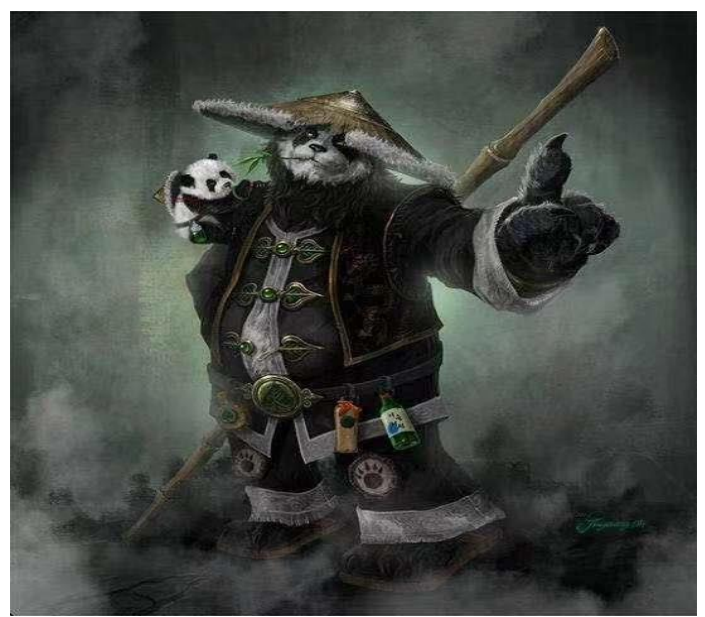

Figure 4 Chinese culture

Pandaren is a race in the World of Warcraft game. Pandaren likes to make friends, share food, and sometimes compete in friendly competitions to enhance their relationship. They are content to live in this insular atmosphere, in which their culture develops without being influenced by the outside world. However, there are still some panda people who crave adventure as much as they crave wine. These adventurers wanted to explore the world beyond the shores of Pandalia. In the 19th century, China was closed to the outside world. The setting of Pandalia is with relevance to this part of Chinese history. Now China has been opening and reforming for 40 years and most of the Chinese are already in line with the international standards, so such setting may lead foreigners to have wrong understandings of the current China.

The excellence of Chinese food culture lies first and foremost in the way that the ingredients are cooked. Compared with other civilized food culture, the Chinese' use of fire is amazing, and there are dozens of cooking methods that would make any national chef feel embarrassed. In the Mists of Pandaria, cooking skills are also greatly enhanced with six sub-divisions for barbecuing, stir-frying, braising, steaming, baking and brewing, each with its own cuisine.

Generally speaking, the origin of wine can be divided into two kinds according to the different brewing materials: wine originated from ancient Caucasus region and rice wine originated from ancient China. In western culture, wine is simply used as a means of social or emotional catharsis, so Dionysus is generally a god of revelry and indulgence. In China, drinking is a kind of philosophy, a mode of thinking and an attitude towards life. Chinese literati and culture have always been inseparable from alcohol. Wine culture, as a representation of Chinese culture, is also valued and reproduced in the game system of World of Warcraft, just like food culture. The way of brewing becomes one of the six branches of giant panda cuisine, while, in WoW, the final battle in the Thunderkeg Brewery recreates the brewing process, as a murloc who is always drunk and drunk can predict the future.
Monk is the best match for the pandaren. The design of this profession contains many elements of Chinese culture. The emergence of monk as a profession reflects Blizzard Entertainment's views on Chinese kung fu culture. It is true that kung fu is part of Chinese culture. However, nowadays Chinese kung fu is mostly used for physical exercise thus what kind of power it has is unknown. Setting up a profession that uses fists and feet to fight is likely to give foreign players the wrong idea about Chinese people and Chinese kung fu culture. However, as a player, the author does have a strong sense of identity and belonging to the profession of monk. The use of cultural appropriation can be said to be successful.

\section{POSITIVE IMPACTS OF CULTURAL ADOPTION IN WORLD OF WARCRAFT}

\subsection{Low Threshold of the Game}

Anyone who can skillfully operate the computer can enter the game without pressure. Even if there is a problem, the official website will provide novice guide to all steps from account registration to understanding the game background and occupation. This has become a guide template for all MMORPGs today. Before WoW, MMO was often considered too high for non-players.

\subsection{Tolerance for Death and Loss}

WoW brings the view that the death penalty should not be too serious, nor affect the fun of the game. On the contrary, WoW only uses mild rejuvenation weakness. Players can also run to their own corpses to revive without seriously affecting the use of equipment. At that time, WoW's main competitor "endless mission" was able to find its own body, but if it could not find it, it would risk losing its equipment and goods. At that time, some players even produced a song called "Did anyone see my body?" as a joke.

\subsection{User Interface Customization}

Currently such interface customization functions can be seen or will be seen in most AAA level MMOs, such as window placement or additional interfaces. Before WoW, this element was not a necessity. But after that, nearly everyone likes it.

The fourth and smaller positive impact is the database of roles, tasks, and items. WoW has its own database where players can search for characters, armor and other information they need. It can be said that WoW provides great convenience and direction. Nowadays, the basic large-scale games have established their own item databases to show the richness and scale of their own games. 


\section{SUGGESTIONS}

\subsection{Improve the Quality of Game Products}

Most of the game models of various domestic games are successful copies of foreign games, only to write a different script. In the development of the game, we should pay attention to the reference and development of the national culture, and integrate the national culture into the game, so that the local game has its own characteristics. As the technology of game $R \& D$ in foreign countries is obviously advanced, Chinese enterprises should avoid technical problems, win by creativity, and even create a new type of game to ensure the quality of game. As a part of entertainment industry, video game industry belongs to cultural industry, so the state should pay equal attention to it, and should not reduce the investment in its development due to the technical difficulty or the bad tendency of public opinion.

\subsection{Increase Support From the State}

The increase of national support, such as piracy and the installation of a large number of private servers, has a great impact on operators, and the problem of plug-in is also very serious, which mainly affects the comfort of the game players and the income of game operators. If China's single player game industry wants to enter the normal development channel, it is necessary to standardize the legislation of cultural industry and put an end to piracy at first; meanwhile, the majority of consumers should also understand and abide by the law and support the legitimate version. The development of video game industry needs the participation and interference of the relevant departments of the whole state.

\section{Conclusion}

The article uses World of Warcraft as a case to study the effects of cultural adoption. Through the analysis of World of Warcraft, several cultural adoption phenomenon can be found, which provide research objects. The Blizzard Entertainment website publishes online user numbers and financial statements for many years and the impact of cultural adoption on corporate profits can be inferred from the analysis of these data. Generally speaking, cultural adoption has more positive impacts on the output of products and the profit of companies. Utilizing culture adoption can make people aware of the culture better and more quickly, and companies can promote their products to customers. There are lots of different cultural elements in World of Warcraft. In particular, Mists of Pandaria has rich Chinese cultural elements, such as kung fu, monks and bamboo hats. This paper only analyzes the cultural adoption in the World of Warcraft, however, in the future, more studies are expected to conduct for better development of video games.

\section{ACKNOWLEDGMENT}

At the completion of the paper, the mood is beyond words. Looking back on the four years of university, time is like an arrow, so fast, I will graduate in a blink of an eye. Looking back at the days in school, I really gained a lot. Especially when I finished this paper, my mood suddenly became bright. During this period, I gained a lot of valuable wealth, including knowledge and social aspects.

First of all, I would like to thank my instructor, Liu Shunling, for correcting the thesis during her busy work. She gave me a lot of guidance and patience. I am admired by the serious and responsible work attitude, and I have gained a lot of motivation. Let me overcome many difficulties in writing the thesis. Thanks again to all the teachers who have assisted me. Thank you for your guidance and help in the past four years, whether in teaching or in your daily life. Your rigorous, serious and responsible attitude is worthy of my continuous progress in the work I will do in the future. I have benefited a lot, and it is my role model. Let me know that no matter what things I face, I have to move forward courageously. I would also like to thank my classmates and friends around me for the past four years. They provided useful suggestions for me when I was the most difficult. With their help and companionship, I can successfully spend a happy college time.

I also want to thank my alma mater for giving me a good learning platform, so that I can gain knowledge and skills here, and lay the foundation for going into society in the future.

Finally, I want to thank my parents for supporting me at all times. You are behind me, giving me trust and support so that I can live and learn better.

\section{REFERENCES}

[1] P. Duarte Elias, T. R. Aurora Pozo, Pamela Beltrani. Smart Reckoning: Reducing the traffic of online multiplayer games using machine learning for movement 
prediction [J]. Entertainment Computing, 2020, p. 33.

[2] Methodological Contributions of Latin American Digital Ethnography Based on the World of Warcraft[J]. Revista Uruguaya de Antropología y Etnografía, 2019, 4(1).

[3] Vladimir Vladimirovich Maltsev, Economics of RPPvP Events in World of Warcraft (via the Example of Argent Dawn Server)[J]. The Computer Games Journal, 2019, 8(3-4).

[4] Poppy Wilde, Adrienne Evans, Empathy at play: Embodying posthuman subjectivities in gaming[J]. Convergence: The International Journal of Research into New Media Technologies, 2019, 25(5-6).

[5] L. Chen, Q. Zhou, Emerging industries under the network environment: online game industry[J]. Economic Frontier, 2003 (2).

[6] Y. C. Feng, Initial Discussion on the Development of E-sports, Zhejiang Sports Science, 2003, (05): 48-51.

[7] J. Yang, J. Z. Guo, On China's Online Game Industry, Journal of Shanghai University, vol. 11, no. 1.

[8] T. Xu, Analysis of the growth of the Chinese game industry [D]. Tsinghua University, 2005, pp. 54-55.

[9] L. Han, Research on China's electronic game industry chain and profit model[D]. Beijing Technology and Business University, 2007, pp. 27-28. 